\title{
The genomics revolution: relevance in healthcare today and tomorrow
}

\author{
The Genetics Symposium was held on 20 April 2012 at the Royal College of Physicians of Edinburgh \\ C Brown \\ Specialty Registrar, Clinical Genetics, Yorkhill Hospital, Glasgow UK \\ Correspondence to C Brown, \\ Ferguson-Smith Centre for \\ Clinical Genetics, Yorkhill, \\ Glasgow G3 8SJ, Scotland, UK \\ DECLARATION OF INTERESTS No conflict of interests declared.

Genetic technology is revolutionising our approach to both rare and common disease. We now have unprecedented access to an individual's genetic code, but this presents clinical and ethical challenges.

\section{SESSION I - GENOMICS IS HERE}

Dr Lucy Raymond (Reader in Neurogenetics and Consultant in Medical Genetics, University of Cambridge) opened the session with an introduction to genomics and a review of her research into intellectual disability. The identification of genetic causes of disease has improved as the resolution of the technology has increased. Genomic medicine can now be used to determine disease risk and predisposition, in diagnosis and prognosis and in the selection and prioritisation of therapeutic options.' In the Genetics of Learning Disability (GOLD) study, sequencing of coding exons in families with $X$-linked mental retardation (XLMR) led to the discovery of nine genes implicated in XLMR (including SYP, ZNF7II and (ASK). It also found that loss of function of $1 \%$ or more of $X$-chromosome genes is compatible with apparently normal existence. ${ }^{2}$

Dr Matthew Hurles (Senior Group Leader, Wellcome Trust Sanger Institute, Cambridge) provided a comprehensive review of challenges and solutions in the interpretation of genome-wide data. Using the Deciphering Developmental Disorders (DDD) project (which aims to identify genetic causes of undiagnosed developmental disorders in children) as an example, the application of array and sequencing technologies and the opportunities, challenges and potential solutions of applying genomic technologies in genetic research were addressed. The project is a UK-wide collaboration involving the Wellcome Trust Sanger Institute (WTSI) and all 23 Regional Genetics Services (RGS). Recruitment of 12,000 patients and their families is planned, with clinical phenotypes recorded and array-comparative genomic hybridisation (array-CGH), single nucleotide polymorphism (SNP) chip and exome sequencing used to identify likely causal variants. Since April 20 I I, I,922 families have been recruited.

Current genome-wide dilemmas in genetic practice were summarised by Professor David FitzPatrick (Professor and Consultant in Clinical Genetics, MRC Human Genetics Unit, University of Edinburgh). There are two main concerns: whether a specific change is pathogenic and whether a pathogenic change is causing the phenotype. Array-CGH has replaced standard karyotype analysis in many centres for the investigation of developmental disorders. Using a case example of 3 q29 microdeletion syndrome, ${ }^{3}$ the utility of the DECIPHER database (decipher.sanger.ac.uk) in clinical interpretation of array-CGH data was described. The complexities of non-penetrance and variable expressivity were also highlighted including a case of reciprocal microduplication 3q29. ${ }^{4}$

\section{SESSION 2 - GENOMICS: RESEARCH TO THE CLINIC, EPILEPSY AS AN EXAMPLE}

Epilepsy kills I,000 people in the UK per year and 30\% or more of patients on antiepileptic drugs do not have seizure control. ${ }^{5}$ Professor Sanjay Sisodiya (Professor of Neurology, UCL Institute of Neurology, London) opened the session with a fascinating summary of the role of genomics as a tool in complementing investigations and management of epilepsy. The importance of reviewing past medical history and phenotype were emphasised using a case example of genetic testing in adulthood leading to the diagnosis of Dravet syndrome (a childhoodonset disorder).

Dr Sameer Zuberi (Consultant Paediatric Neurologist, Royal Hospital for Sick Children, Yorkhill, Glasgow) gave a stimulating talk outlining a practical approach to genetic testing in epilepsy. In 2005 a joint clinical and molecular genetic testing service for epilepsy was established at the Royal Hospital for Sick Children in Glasgow. Genes associated with epilepsy currently 
being tested are STXBPI, SCNIA, PCDHI9, ARX, CDKL5 and SLC2A I. Chromosomal disorders strongly associated with epilepsy include Wolf-Hirschhorn Syndrome (4p-), Miller-Dieker Syndrome (del 17p/3.3), Angelman syndrome, inversion duplication 15 syndrome, terminal deletion chromosome Ip36, ring chromosome 14 syndrome and ring chromosome 20 syndrome. ${ }^{6}$ Using specific case examples, the role of genetics in epilepsy and the use of targeted genetic testing in saving patients from otherwise invasive investigations was further reviewed. ${ }^{7-9}$ One such example is Dravet syndrome (severe myoclonic epilepsy in infancy). In $90 \%$ of well characterised cases there are mutations in the SCNIA gene. Lamotrigine and carbamazepine can worsen seizures but stiripentol and bromides are beneficial. ${ }^{10}$

\section{STANLEY DAVIDSON LECTURE}

Professor Han Brunner (Professor of Medical Genetics, Radboud University Nijmegen Medical Centre, The Netherlands) delivered an illuminating account of his experience using genome-wide technologies. In his talk, 'How genome sequencing changes medicine', he described how exome sequencing in just two patients affected with the rare, recessive,Sensenbrenner syndrome (cranioectodermal dysplasia)," led to the discovery of the WDR35 gene. Also discussed was the fact that a large fraction of unexplained intellectual disability may be due to de novo autosomal dominant single gene mutations. These mutations can be detected efficiently by exome sequencing of patient-parent trios. ${ }^{12}$

\section{SESSION 3 - GENOMICS DRIVING TREATMENT}

Dr Bill Newman (Senior Clinical Lecturer in Genetic Medicine, University of Manchester) provided a comprehensive review of advances in the genetics of targeting therapy to treatment. Advances in technology have facilitated studies to define novel genetic variants that are important in predicting an individual's response to, or risk of, side-effects from a range of different treatments. A total of $15 \%$ of inpatients experience adverse drug reactions. ${ }^{13}$ The value of pharmacogenomics in avoiding adverse drug reactions, improving drug efficacy, drug development and to resurrect 'failed drugs' was reviewed. An example of altered practice is the use of HLA genotyping in human immunodeficiency syndrome (HIV) treatment prior to prescription of the antiretroviral agent abacavir, which can be fatal on re-exposure following adverse reaction. The HLA-B*570I genotype is strongly associated with this adverse drug reaction. ${ }^{14}$ Testing was adopted in the UK and Australia and there has been a reduction in adverse drug reactions from $\sim 5 \%$ to $0.5 \% .^{15}$
Other advances have been in acquired (somatic) mutation testing in tumour samples to predict response to molecularly targeted agents. Screening of all tumours for a panel of somatic mutations in order to direct most appropriate treatment is planned in the future.

\section{SESSION 4 - TREATMENT DEVELOPMENT IN RARE GENETIC DISEASES: N IS FOR NETWORK}

Although the genetic cause of Huntington's disease (HD) was identified twenty years ago, we do not as yet have any treatment that cures or modifies the progression of the disease. Professor Joaquim Ferriera (Scientific Director of European Huntington's Disease Network and Professor of Neurology and Pharmacology, University Hospital of Santa Maria, Lisbon, Portugal) explained that with many potential drugs expected to advance from preclinical to clinical stage, there will be additional demand for worldwide collaboration.

To overcome current limitations in research and create large samples in a rare disease field, establishing international networks of physicians, allied health professionals, researchers, patient associations and clinical centres is essential. The European Huntington Disease Network (EHDN) is an example of such a network which provides the structure to facilitate the development of clinical research in HD. There is also a global HD cohort study, Enroll-HD, which combines European, North American and Australian studies with the new Latin American HD Network.

The symposium concluded with a thought-provoking ethical debate with each speaker presenting their view on the question: 'The more we learn the harder it gets - how much should patients be told?'. Professor Andrew Green (Professor of Medical Genetics, University College Dublin) argued that the significant amounts of incidental genetic information being created results in a dilemma for researchers and research participants in deciding how much information subjects should be given. There are no firm regulations and general guidelines encompassing both research and private sector arenas are going to be necessary to help researchers, clinicians and patients make this decision. Professor Graeme Laurie (Professor of Medical Jurisprudence, University of Edinburgh) argued that legal duty of care requires that physicians provide a reasonable standard of care, but in the case of disclosure of genetic information, there is disagreement about what constitutes reasonable and responsible courses of action. Existing ethical and legal concepts (such as autonomy and confidentiality) are of limited assistance. Informed discussion and debate is the first step in deciding what counts as good practice in these difficult circumstances. 


\section{TAKE-HOME MESSAGE}

With rapidly advancing and increasingly available genetic technology there is more potential than ever before for the role of genomics in the investigation and management of patients. However, current issues in the use of genome-wide data include challenges regarding data interpretation and ethical dilemmas. It is predicted that discussion and collaboration among colleagues will play an even greater role in the future.

\section{REFERENCES}

I House of Lords Science and Technology Committee. Genomic medicine; 2nd report of session 2008-2009. London: House of Lords; 2009.

2 Tarpey PS, Smith R, Pleasance E et al. A systematic, large-scale resequencing screen of $X$-chromosome coding exons in mental retardation. Nat Genet 2009; 41:535-43. http://dx.doi.org// 0.1038/ ng.367

3 Willatt L, Cox J, Barber J et al. 3q29 microdeletion syndrome: clinical and molecular characterization of a new syndrome. Am J Hum Genet 2005; 77:I54-60. http://dx.doi.org/I0.1086/43I653

4 Goobie S, Knijnenburg J, Fitzpatrick D et al. Molecular and clinical characterization of de novo and familial cases with microduplication 3q29: guidelines for copy number variation case reporting. Cytogenet Genome Res 2008; 123:65-78. http://dx.doi.org/I0.I I59/000184693

5 National Institute for Clinical Excellence. National clinical audit of epilepsy-related death [Internet]. London: NICE; 2002 [cited 2012 jun 2I]. Available from: http://www.nice.org.uk/media/94E/3C/ epilepsyreport.pdf

6 Zuberi SM. Chromosome disorders associated with epileptic seizures. In: Panayiotopoulos CP, Benbadis SR, Beran RG et al, editors. Atlas of epilepsies. Springer 2010. pp.I21-7. http://dx.doi. org/10.1007/978-I-84882-128-6_I7

7 Depienne C, Trouillard O, Saint-Martin C et al. Spectrum of SCNIA gene mutations associated with Dravet syndrome: analysis of 333 patients. J Med Genet 2009; 46:183-9l. http://dx.doi. org/I0.II36/jmg.2008.062323

8 Heron SE, Cox K, Grinton BE et al. Deletions or duplications in KCNQ2 can cause benign familial neonatal seizures. J Med Genet 2007; 44:79I-6. http://dx.doi.org/I0.1 I36/jmg.2007.05I938
9 Deprez L, Weckhuysen S, Holmgren P et al. Clinical spectrum of early-onset epileptic encephalopathies associated with STXBPI mutations. Neurology 2010; 75:I 159-65. http://dx.doi.org//0.12/2/ WNL.0b0I3e318If4d7bf

10 Chiron C, Marchand MC, Tran A et al. Stiripentol in severe myoclonic epilepsy in infancy: a randomised placebo-controlled syndrome-dedicated trial. STICLO study group. Lancet 2000; 356:1638-42. http://dx.doi.org/I0.10I6/S0I40-6736(00)03I57-3

II Konstantinidou A, Fryssira H, Sifakis S et al. Cranioectodermal dysplasia: a probable ciliopathy. Am J Med Genet A 2009; I 49A:2206I I. http://dx.doi.org//0.1002/ajmg.a.33013

12 Vissers LE, de Ligt J, Gilissen $C$ et al. A de novo paradigm for mental retardation. Nat Genet 2010; 42:1109-12. http://dx.doi. org/10.1038/ng.712

I3 Davies EC, Green CF, Taylor S et al. Adverse drug reactions in hospital in-patients: a prospective analysis of 3695 patient episodes. PLoS One 2009; 4:e4439. http://dx.doi.org/l0.137I/ journal.pone.0004439

14 Hughes DA, Vilar FJ, Ward CC et al. Cost-effective analysis of HLA B*570I genotyping in preventing abacavir hypersensitivity. Pharmacogenetics 2004; I4:335-42. http://dx.doi.org/I0. I097/0000857I200406000-00002

I5 Mallal S, Phillips E, Carosi G et al. HLA-B*570I screening for hypersensitivity to abacavir. N Engl J Med 2008; 358:568-79. http:// dx.doi.org/ I0.1056/NEJMoa0706 | 357| |-200406000-00002 